\title{
Home monitoring for glaucoma
}

\author{
Jemaima Che Hamzah ${ }^{1}$ - Qëndresë Daka $\mathbb{1}^{2} \cdot$ Augusto Azuara-Blanco $^{3}$
}

Received: 29 June 2019 / Revised: 25 September 2019 / Accepted: 9 October 2019 / Published online: 26 November 2019

(c) The Author(s), under exclusive licence to The Royal College of Ophthalmologists 2019

\begin{abstract}
Glaucoma services are overwhelmed and struggling to accommodate current demand. Reducing the need for hospital based services would improve our ability to see those most at risk of vision loss, which could both reduce demand and improve patient outcomes. Digital technologies that provide opportunities for home monitoring of glaucoma progression have potential to contribute to solve these challenges and, potentially, improve glaucoma care. This article will review the literatures of well-established technologies that support home monitoring for glaucoma, specifically home tonometry (with rebound tonometry) and perimetry with Moorfields Motion Displacement Test and Melbourne Rapid Field.
\end{abstract}

\section{Introduction}

Glaucoma is a group of eye disorders that cause optic neuropathy with characteristic cupping of the optic nerve and visual field (VF) changes. If left untreated, glaucoma can lead to visual impairment and blindness. The Vision Loss Expert Group of the Global Burden of Disease Study has reported that glaucoma is the most common cause of irreversible blindness in the world together with age-related macular degeneration in their meta-analysis [1]. The only treatment proven successful to stop development of glaucoma and reduce progression of the disease is by lowering intraocular pressure (IOP) [2-5]. Once diagnosed, patients need to be on lifelong treatment and follow-up.

Monitoring of glaucoma requires measurement of IOP and assessment of functional and structural parameters of optic nerve. Any change in patients' treatment plan depends on the level of IOP (and response to the medication) and deterioration of $\mathrm{VF}$ and/or optic nerve and/or structural assessments of the retina. However, all measurements are

Augusto Azuara-Blanco

a.azuara-blanco@qub.ac.uk

1 Department of Ophthalmology, Faculty of Medicine, Universiti Kebangsaan Malaysia, Kuala Lumpur, Malaysia

2 Department of Pathophysiology, Medical Faculty, University of Prishtina, Prishtinë, Kosovo

3 Centre for Public Health, School of Medicine, Dentistry and Biomedical Sciences, Queen's University Belfast, Belfast, UK subjected to fluctuation and patients require frequent follow-up to determine whether a change has occurred.

A high IOP is a major risk factor for progression of glaucoma [6-8]. Measurement of IOP is usually taken in the clinic, but studies have shown more than $50-75 \%$ of IOP peaks occur outside clinic hours $[9,10]$. IOP diurnal profile as well as peaks can be assessed by monitoring the IOP for $24 \mathrm{~h}$ but this needs the patients to be admitted for repeated measurements. This practice is time and resource consuming, which is rarely feasible in routine practice.

VF progression is usually detected by looking through a series of VF examinations obtained over a period of time, possibly several years or more [11]. It has been proposed that it would take 6 years to detect a relatively fast progression rate of $1 \mathrm{~dB}$ per year if only one VF test was performed per year [12]. Confirmation of deterioration can be reduced if repeat examinations are performed in a shorter period i.e., VF progression can be seen in 2 years if three examinations were performed each year [12]. In order to diagnose true disease progression from measurement variability inherent in the VF data, the authors recommended six VF tests to be performed in the first 2 years after diagnosis to help in determining rate of progression in a glaucoma patient.

Currently, patients need to travel to the hospital to have their IOP and VFs checked by the eye healthcare professionals. Despite the potential benefits of increased testing frequency, current healthcare systems do not have capacity for repeated, multiple testing within a year. In addition the need for frequent visits to hospital is also an inconvenience to patients and carers. 
Innovations of medical devices may help overcome some of the monitoring challenges with frequent measurements of IOP and VF. Increasing availability of home monitoring devices may play an important role to detect uncontrolled or progressive disease, and also reassure patients that the glaucoma is well controlled. Home monitoring of IOP and VFs can give more data on measurements and help to better monitor the glaucoma.

\section{Home intraocular pressure monitoring}

Various devices has been designed to measure 24-h IOP such as integration of IOP sensors into intraocular lenses after cataract extraction surgery [13, 14], implantable IOP sensor placed either in the ciliary sulcus or the capsular bag [15, 16] and contact lens sensor [17]. However, the implantable devices have only been used in very few human studies with preliminary results, and would be available only in people undergoing intraocular surgery, while IOP readings of the contact lens sensor are in units rather than $\mathrm{mmHg}$ with no available conversion method yet.

A potential and practical option to measure 24-h IOP is to measure patients' own IOP using a tonometer designed for self-tonometry. Rebound tonometry developed by Icare (Finland Oy) has been used since 2003 and has demonstrated to have high agreement with the standard tonometry, Goldmann applanation tonometry (GAT) [18]. These devices are easy to use and do not require the use of topical anesthesia making them potentially ideal for home monitoring. Rebound tonometry measures IOP using the impact/ induction principle [19]. The IOP is quantified by measuring the deceleration of a magnetized disposable probe as it rebounds from the surface of the cornea [20].

A new Icare tonometry, Icare HOME (TA022; Icare Finland $\mathrm{Oy}$ ) is currently available for home IOP monitoring (Fig. 1). Icare HOME is a handheld rebound tonometer that has an automatic-side recognition and positioning assistant for the correct alignment of the tonometer [21] compared with its predecessor. During measurement, Icare Home is placed at $4-8 \mathrm{~mm}$ from the cornea where the inbuilt software acquires six readings. The highest and lowest IOP readings are eliminated, leaving four readings which are be averaged and displayed on the device. If reliable readings are not obtained, an error bar is displayed and patients will need to repeat the measurements. The Icare HOME stores the final IOP with other information such as date, time, laterality of the eye, and measurement quality into its builtin memory module [22]. Icare HOME can be linked to the patient's smartphone and data can be uploaded and retrieved from the cloud allowing remote access to the data. Home tonometry can be used by the patient or by another person.

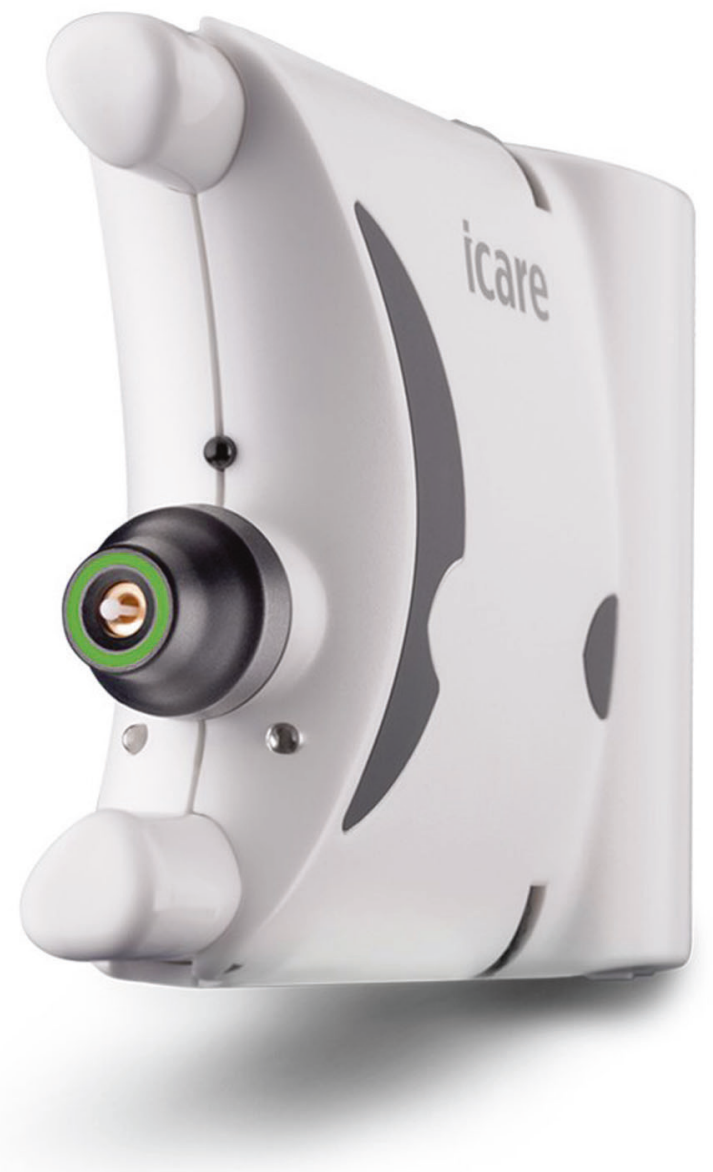

Fig. 1 Icare $^{\circledast}$ HOME tonometer (TA022; Icare Finland Oy)

Icare HOME showed good repeatability in a study by Valero et al., who reported an intra-class correlation value of 0.872 of three repeated measurements by patients, although no coefficients of repeatability (more informative) were not estimated. There is moderate agreement between Icare HOME and GAT in glaucoma patients (Table 1) [20-32]. Most patients are able to measure their own IOP at home after given appropriate training and instruction [24, 26]. However, high intraindividual variation in diurnal IOP was seen across consecutive days as subjects exhibit different diurnal curve from day to day [27-29].

\section{Home visual field monitoring}

Recently, there are several tablet-based devices and headmounted displays that have been developed to measure VF away from clinical setting [23]. These devices could be potentially performed by patients without direct supervision of a trained eye care health professional with prior training making it possible for patients with glaucoma to monitor their VF at home. Tablet-based devices, such as Moorfields Motion Displacement Test (MMDT) and Melbourne Rapid Field (MRF), are currently available for use, while 


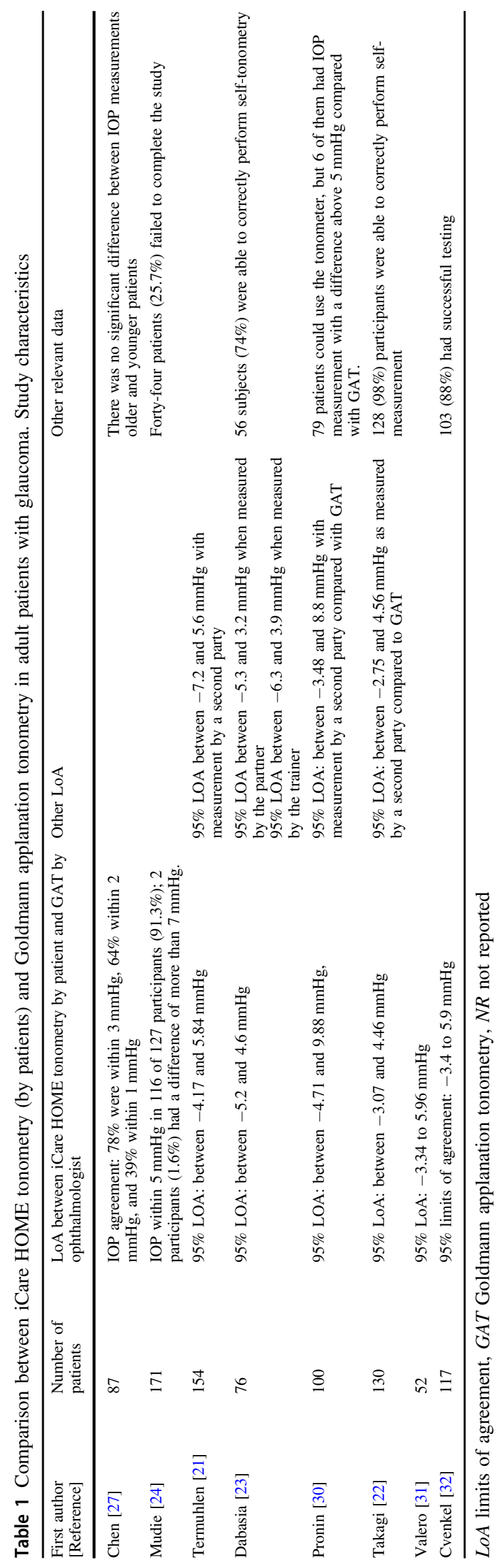

head-mounted displays, such as IMO [33] and Virtual Eye [34], are still in the preliminary stages of development.

\section{Moorfields Motion Displacement Test (MMDT)}

MMDT is computer-based software program for VFs testing in the community [35]. It is designed to run on a laptop computer. The test uses vertical white line stimuli at 31 test locations which spatially corresponds to Humphrey Visual Field Analyzer (HFA), Swedish interactive threshold algorithm (SITA) 24-2 [Carl Zeiss Meditec, Dublin, CA]) test locations. These stimuli are presented continuously throughout the test, against a gray background. The test locations were scaled by estimates of retinal ganglion cell density and selected using the Garway-Heath anatomical map [36, 37].

One eye is tested at a time using enhanced suprathreshold screening algorithm (ESTA) 99.5 program. ESTA 99.5 program presents displacements at the 95 centile, according to normative values derived in the UK from a population familiar with modern technology [35]. Patients place their head in a collapsible chin and forehead rest mounted on the laptop and set at $30 \mathrm{~cm}$ from the computer screen where the eyes can be aligned directly to a central white spot on the screen. Patients are instructed to look steadily at the central white spot throughout the test and press the computer mouse or spacebar every time they see a line move on the screen. Test is performed in a dim illumination room of approximately 85 lux. Average time need to complete the VF test using MMDT is about $5 \mathrm{~min}$ for both eyes. This test is designed to overcome the effects of cataract and uncorrected refractive error; therefore patients can perform MMDT without any refractive correction.

An index which measures the VF defect, the global probability of true damage (GPTD) can be calculated by summation of the probability of true damage derived from each of the 31 locations. The GPTD is expressed in quotient of $100(0-100 \%)$, where higher GPTD values represent a greater probability of damage. GPTD value ranges from 0.31 to 31 [35-38]. Test reliability is determined by falsepositive (FP) response rate. False positive is recorded when responses are $<180 \mathrm{~ms}$ from the time the stimulus presented. False negative is usually not recorded as patients with glaucoma have fluctuating results and high false-negative results [38]. The recommended pass-fail and reliability criteria are a GPTD $\geq 3$, and FP response rate $\leq 15 \%$ [35]. The test repeatability of the MMDT was reported as "good" by Loughman et al. using LoA plots and coefficient of repeatability [35].

The GPTD index had an AUC of 0.930 (95\% CI [0.893-0.967]) for discriminating glaucoma from nonglaucomatous eyes with a sensitivity of $88.5 \%$ and specificity of $85 \%$ in a population-based setting [38]. Severity of 
glaucoma was mild in 17 , moderate in 27 , and advanced in 34 participants. It is difficult to compare with the standard HFA results as MMDT is a suprathreshold test and there are no similar global indices, such as mean deviation (MD) or pattern standard deviation. Test is easy to administer but may be challenging to some computer naive persons. This is probably due to strain in using the computer mouse as a response button for an extended period of the time during the test. However, performance between older, less educated computer naive subjects was similar to young computer-familiar subjects [35].

\section{Melbourne Rapid Fields (MRF)}

MRF (GLANCE Optical Pty Ltd, Melbourne, Australia) is a tangent perimeter application developed on iPad tablet platform (Apple, Cupertino, California, USA). As iPad tablets are portable and commonly available, it allows VF testing outside of clinic and in remote areas. Furthermore, it raises a possibility to be used by patients with glaucoma to perform VF tests at home unsupervised with minimal training [39-43].

Test should be performed in a quiet, dimly lit room with screen brightness automatically adjusted to maximal hardware brightness by the app at the start of the testing procedure. One eye is tested at a time and the fellow eye is patched. Patient is seated comfortably at a table with an iPad tablet placed on a typing stand accompanied by a Bluetooth keyboard. Patients view the 9.7-in. iPad tablet device (iPad 3 or later) at $33 \mathrm{~cm}$ wearing their normal reading glasses measured by a fixed piece of string from the iPad screen to bridge of patient's nose at the start of the test. Head position is maintained throughout the test.

The testing grid consist of 66 test locations placed in a radial pattern covering $34^{\circ}$ horizontal and $25^{\circ}$ vertical of the VF. At the start of the test, blind spot will be located, and a stimulus will be presented about 8-10 times in this location throughout the test using central fixation. Testing will then occur in two phases: an initial central field test (36 points tested with fixation in the center of the screen) followed by a peripheral field test (30 test points) where patient fixate at each corner of the iPad screen sequentially to increase target eccentricity [39]. Location of the blind spot is not implemented during peripheral testing. FP and false-negative checks are presented throughout the test. FP checks are performed by using a interspacing periods (1000-1400 ms) throughout the test during which no stimulus is presented on the screen and recorded when patients gives a respond during this period [39].

A voice commands (in English language) generated by the tablet is provided to guide the patients throughout the test. Patients respond to the stimulus is recorded using the spacebar on the bluetooth keyboard. This method was selected because smear of finger marks on the screen can make the screen dirty and obscure a stimulus. It also provides a better tactile feedback to patients. Testing may take 4-6 min, depending on the nature of the field loss and reliability of the patient. Average test duration for the MRF was shown to be statistically significant faster $(5.7 \pm 0.1$ min) compared with the average HFA SITA Standard 24-2 test time $(6.3 \pm 0.1 \mathrm{~min})$ [39].

MD and pattern deviation can be calculated from the MRF. MD was calculated from the average point-wise deviations using the age-adjusted expectation returned from the analysis of 17,390 thresholds adjusted for grid and size effect [39]. While, PD was calculated using a standard formulae as the average residual after allowing for the patient's MD [39]. In terms of perimetric results, MD and PD results from MRF were in agreement and correlate with MD from HFA SITA Standard 24-2 (MD ICC = 0.93, PD $\mathrm{ICC}=0.86)[40,41]$. Test-retest reliability was also shown to be comparable with HFA SITA Standard 24-2 with ICC of 0.93 for MD and 0.89 for PD. However, MRF recorded a statistically higher percentage of fixation losses $(36 \pm 4 \%)$ compared with the HFA $(6 \pm 1 \%)$ which may be due to freespace viewing corrupting the blind-spot monitor [40]. Bland-Altman analysis showed a small bias of $1.4 \mathrm{~dB}$, with less negative MD returned by MRF [41]. In terms of scotoma detection using the cluster criteria the MRF on repeat testing detected 31/36 of abnormal hemifields in manifest glaucoma patients on the second test [44].

MRF looks promising as a portable tangent perimeter but further research is required before it can be widely implemented for home monitoring of VF. The current studies were conducted in a controlled environment with strict control of viewing distance and environment. Proper instructions and training to use the device unsupervised at home will be needed for the patients and to achieve reliable $\mathrm{VF}$ results.

It is common practice to use imaging technologies to monitor patients with glaucoma and detection of structural progression often influences clinical decisions. There are attempts to develop portable low-cost optical coherence tomography that, theoretically, could further support the goal of home monitoring [45, 46].

\section{Conclusion}

Detection of glaucoma progression requires regular IOP and VF monitoring in the eye outpatient clinics. However, these visits are time consuming, expensive, and difficult for patients. With the invention of newer "smart" technology, IOP devices, and VF tablet applications allows home monitoring of glaucoma providing abundant priceless data, which could provide a better understanding about the effects 
of treatment to patients and improve patients care. Home monitoring may also increase patients' engagement and help in the patients' adherence to their medication. Apart from that, home monitoring may also lead to more affordable diagnostic tests and available to individual with limited access to healthcare. Future research may be directed to validate the current applications and devices and invention of wearable device for home monitoring of glaucoma.

\section{Compliance with ethical standards}

Conflict of interest The authors declare that they have no conflict of interest.

Publisher's note Springer Nature remains neutral with regard to jurisdictional claims in published maps and institutional affiliations.

\section{References}

1. Bourne RR, Taylor HR, Flaxman SR, Keefe J, Leasher J, Naidoo $\mathrm{K}$, et al. Number of people blind or visually impaired by glaucoma worldwide and in world regions 1990-2010: a meta-analysis. PLoS One. 2016;11:e0162229 https://doi.org/10.1371/journal. pone.0162229.

2. Boland MV, Ervin AM, Friedman DS, Jampel HD, Hawkins BS, Vollenweider D, et al. Comparative effectiveness of treatments for open-angle glaucoma: a systematic review for the U.S. Preventive Services Task Force. Ann Intern Med. 2013;158:271-9. https:// doi.org/10.7326/0003-4819-158-4-201302190-00008.

3. Kass MA, Heuer DK, Higginbotham EJ, Johnson CA, Keltner JL, Miller JP, et al. The Ocular Hypertension Treatment Study: a randomized trial determines that topical ocular hypotensive medication delays or prevents the onset of primary open-angle glaucoma. Arch Ophthalmol. 2002;120:701-13.

4. Heijl A, Leske MC, Bengtsson B, Hyman L, Bengtsson B, Hussein M. Reduction of intraocular pressure and glaucoma progression: results from the Early Manifest Glaucoma Trial. Arch Ophthalmol. 2002;120:1268-79.

5. Investigators TA. The Advanced Glaucoma Intervention Study (AGIS): 7. The relationship between control of intraocular pressure and visual field deterioration. The AGIS Investigators. Am J Ophthalmol. 2000;130:429-40.

6. Konstas AG, Quaranta L, Mikropoulos DG, Nars MB, Jaffee A, et al. Peak intraocular pressure and glaucomatous progression in primary open-angle glaucoma. J Ocul Pharmacol Therapeutics. 2012;28:26-32. https://doi.org/10.1089/jop.2011.0081.

7. De Moraes CG, Juthani VJ, Liebmann JM, Teng CC, Tello C, Sussanna R Jr, et al. Risk factors for visual field progression in treated glaucoma. Arch Ophthalmol. 2011;129:562-8. https://doi. org/10.1001/archophthalmol.2011.72.

8. Gardiner SK, Johnson CA, Demirel S. Factors predicting the rate of functional progression in early and suspected glaucoma. Investig Ophthalmol Vis Sci. 2012;53:3598-604. https://doi.org/ 10.1167/iovs.11-9065.

9. Barkana Y, Anis S, Liebmann J, Tello C, Ritch R. Clinical utility of intraocular pressure monitoring outside of normal office hours in patients with glaucoma. Arch Ophthalmol. 2006;124:793-7. https://doi.org/10.1001/archopht.124.6.793.

10. Liu JH, Kripke DF, Twa MD, Hoffman RE, Mansberger SL, Rex $\mathrm{KM}$, et al. Twenty-four-hour pattern of intraocular pressure in the aging population. Investig Ophthalmol Vis Sci. 1999;40:2912-7.
11. Schulzer M. Errors in the diagnosis of visual field progression in normal-tension glaucoma. Ophthalmology. 1994;101:1589-94.

12. Chauhan BC, Garway-Heath DF, Goni FJ, Rosetti L, Bengtsson $\mathrm{B}$, Viswanathan AC, et al. Practical recommendations for measuring rates of visual field change in glaucoma. $\mathrm{Br} \mathrm{J}$ Ophthalmol. 2008;92:569-73. https://doi.org/10.1136/bjo.2007.135012.

13. Walter P, Schnakenberg U, vom Bogel G, Ruokonen P, Kruger C, Dinslage S, et al. Development of a completely encapsulated intraocular pressure sensor. Ophthalmic Res. 2000;32:278-84. https://doi.org/10.1159/000055626.

14. Paschalis EI, Cade F, Melki S, Pasquale LR, Dohlman CH, Ciolino JB. Reliable intraocular pressure measurement using automated radio-wave telemetry. Clin Ophthalmol. 2014;8:177-85. https://doi.org/10.2147/opth.S54753.

15. Melki S, Todani A, Cherfan G. An implantable intraocular pressure transducer: initial safety outcomes. JAMA Ophthalmol. 2014;132:1221-5. https://doi.org/10.1001/jamaophthalmol.2014. 1739 .

16. Koutsonas A, Walter P, Roessler G, Plange N. Implantation of a novel telemetric intraocular pressure sensor in patients with glaucoma (ARGOS study): 1-year results. Investig Ophthalmol Vis Sci. 2015;56:1063-9. https://doi.org/10.1167/iovs.1414925.

17. Leonardi M, Leuenberger P, Bertrand D, Bertsch A, Renaud P. First steps toward noninvasive intraocular pressure monitoring with a sensing contact lens. Investig Ophthalmol Vis Sci. 2004;45:3113-7. https://doi.org/10.1167/iovs.04-0015.

18. Burr JM, Botello-Pinzon P, Takwoingi Y, Hernandez R, VazquezMontes M, et al. Surveillance for ocular hypertension: an evidence synthesis and economic evaluation. Health Technol Assess. 2012;16:1-271. https://doi.org/10.3310/hta16290.

19. Kontiola AI. A new induction-based impact method for measuring intraocular pressure. Acta Ophthalmol Scand. 2000;78:142-5.

20. Boote T, Tatham AJ. Home monitoring in glaucoma. Eur Ophthalmic Rev. 2018;12:3.

21. Termuhlen J, Mihailovic N, Alnawaiseh M, Dietlein TS, Rosentreter A. Accuracy of measurements with the iCare HOME rebound tonometer. J Glaucoma. 2016;25:533-8. https://doi.org/ 10.1097/ijg.0000000000000390.

22. Takagi D, Sawada A, Yamamoto T. Evaluation of a new rebound self-tonometer, Icare HOME: comparison with goldmann applanation tonometer. J Glaucoma. 2017;26:613-18. https://doi.org/ 10.1097/ijg.0000000000000674.

23. Dabasia PL, Lawrenson JG, Murdoch IE. Evaluation of a new rebound tonometer for self measurement of intraocular pressure. Br J Ophthalmol. 2016;100:1139-43.

24. Mudie LI, LaBarre S, Varadaraj V, Karahus S, Onnela J, Munox B, et al. The Icare HOME (TA022) Study: performance of an intraocular pressure measuring device for self-tonometry by glaucoma patients. Ophthalmology. 2016;123:1675-84. https:// doi.org/10.1016/j.ophtha.2016.04.044.

25. Sakamoto M, Kanamori A, Fujihara M, Yamada Y, Nakamura M, Negi A. Assessment of IcareONE rebound tonometer for selfmeasuring intraocular pressure. Acta Ophthalmol. 2014;92:243-8. https://doi.org/10.1111/aos.12108.

26. Rosentreter A, Jablonski KS, Mellein AC, Gaki S, Hueber A, Dietlein TS. A new rebound tonometer for home monitoring of intraocular pressure. Graefes Arch Clin Exp Ophthalmol. 2011;249:1713-9. https://doi.org/10.1007/s00417-011-1785-7.

27. Chen E, Querat L, Akerstedt C. Self-tonometry as a complement in the investigation of glaucoma patients. Acta Ophthalmol. 2016;94:788-92. https://doi.org/10.1111/aos.13129.

28. Querat L, Chen E. Monitoring daily intraocular pressure fluctuations with self-tonometry in healthy subjects. Acta Ophthalmol. 2017;95:525-29. https://doi.org/10.1111/aos.13389. 
29. Huang J, Katalinic P, Kalloniatis M, Hennessy MP, Xangerl B. Diurnal intraocular pressure fluctuations with self-tonometry in glaucoma patients and suspects: a clinical trial. Optom Vis Sci. 2018;95:88-95. https://doi.org/10.1097/opx.0000000000001172.

30. Pronin S, Brown L, Megaw R, Tatham AJ. Measurement of intraocular pressure by patients with glaucoma. JAMA Ophthalmol. 2017;135:1-7.

31. Valero B, Fenolland JR, Rosenberg R, Sendon D, Mesnard C, Sigaus $\mathrm{M}$, et al. Reliability and reproducibility of intraocular pressure (IOP) measurement with the Icare(R) Home rebound tonometer (model TA022) and comparison with Goldmann applanation tonometer in glaucoma patients. J Fr Ophtalmol. 2017;40:865-75.

32. Cvenkel B, Velkovska MA, Jordanova VD. Self-measurement with Icare HOME tonometer, patients' feasibility and acceptability. Eur J Ophthalmol. 2019;11:1120672118823124.

33. Matsumoto $\mathrm{C}$, Yamao $\mathrm{S}$, Nomoto $\mathrm{H}$, Takada S, Okuyama $\mathrm{S}$, Kimura S, et al. Visual field testing with head-mounted perimeter 'imo'. PLoS One. 2016;11:e0161974 https://doi.org/10.1371/ journal.pone.0161974.

34. Wroblewski D, Francis BA, Sadun A, Vakili G, Chopra V. Testing of visual field with virtual reality goggles in manual and visual grasp modes. Biomed Res Int. 2014;2014:206082 https:// doi.org/10.1155/2014/206082.

35. Loughman J, Alvarez CG, Verdon-Roe GM, Anderson R, Manuel RA, Naidoo K. Impact of computer experience on the viability and repeatability of the moorfields motion displacement test in a developing and underserved african setting. J Clin Exp Ophthalmol. 2013;4:6 https://doi.org/10.4172/2155-9570. 1000304

36. Garway-Heath DF, Caprioli J, Fitzke FW, Hitchings RA. Scaling the hill of vision: the physiological relationship between light sensitivity and ganglion cell numbers. Investig Ophthalmol Vis Sci. 2000;41:1774-82.
37. Garway-Heath DF, Poinoosawmy D, Fitzke FW, Hitchings RA. Mapping the visual field to the optic disc in normal tension glaucoma eyes. Ophthalmology. 2000;107:1809-15.

38. Ong EL, Zheng Y, Aung T, Tan L, Cheng CY, Wong TY, et al. Performance of the Moorfields motion displacement test for identifying eyes with glaucoma. Ophthalmology. 2014;121:88-92. https://doi.org/10.1016/j.ophtha.2013.08.036.

39. Vingrys AJ, Healey JK, Liew S, Saharinen V, Tran M, Wu W, et al. Validation of a Tablet as a Tangent Perimeter. Transl Vis Sci Technol. 2016;5:3 https://doi.org/10.1167/tvst.5.4.3.

40. Prea SM, Kong YXG, Mehta A, He M, Crowston JG, Gupta V, et al. Six-month longitudinal comparison of a portable tablet perimeter with the humphrey field analyzer. Am J Ophthalmol. 2018;190:9-16. https://doi.org/10.1016/j.ajo.2018.03.009.

41. Kong YX, He M, Crowston JG, Vingrys AJ. A comparison of perimetric results from a tablet perimeter and humphrey field analyzer in glaucoma patients. Transl Vis Sci Technol. 2016;5:2 https://doi.org/10.1167/tvst.5.6.2.

42. Sample PA, Dannheim F, Artes PH, Dietzsch J, Henson D, Johnson CA, et al. Imaging and perimetry society standards and guidelines. Optom Vis Sci. 2011;88:4-7. https://doi.org/10.1097/ OPX.0b013e3181fc3735.

43. Anderson AJ, Bedggood PA, George Kong YX, Martin KR, Vingrys AJ. Can home monitoring allow earlier detection of rapid visual field progression in glaucoma? Ophthalmology. 2017;124:1735-42.

44. Schulz AM, Graham EC, You Y, Klistorner A, Graham SL. Performance of iPad-based threshold perimetry in glaucoma and controls. Clin Exp Ophthalmol. 2018;46:346-55.

45. Song G, Chu KK, Kim S, Crose M, Cox B, Jelly ET, et al. First clinical application of low-cost OCT. Transl Vis Sci Technol. 2019;28:61.

46. Kim S, Crose M, Eldridge WJ, Cox B, Brown WJ, Wax A. Design and implementationof a low-cost, portable OCT system. Biomed Opt Express. 2018;20:1232-43. 